ARTICLE

Received 15 Mar 2013 | Accepted 17 Jul 2013 | Published 9 Aug 2013 DOl: 10.1038/ncomms3321

\title{
Polymeric pseudo-crown ether for cation recognition via cation template-assisted cyclopolymerization
}

Takaya Terashima ${ }^{1}$, Minami Kawabe$^{1}$, Yuichiro Miyabara ${ }^{1}$, Hiroaki Yoda ${ }^{1} \&$ Mitsuo Sawamoto ${ }^{1}$

Cyclopolymerization is a chain polymerization of bifunctional monomers via alternating processes of intramolecular cyclization and intermolecular addition, to give soluble linear polymers consisting of in-chain cyclic structures. Though cyclopolymers comprising in-chain multiple large rings potentially show unique functionality, they generally require the elaborate design of bifunctional monomers. Here we report cation template-assisted cyclopolymerization of poly(ethylene glycol) dimethacrylates as an efficient strategy directly yielding polymeric pseudo-crown ethers with large in-chain cavities (up to 30-membered rings) for selective molecular recognition. The key is to select a size-fit metal cation for the spacer unit of the divinyl monomers to form a pseudo-cyclic conformation, where the two vinyl groups are suitably positioned for intramolecular cyclization. The marriage of supramolecular chemistry and polymer chemistry affords efficient, one-pot chemical transformation from common chemical reagents with simple templates to functional cyclopolymers.

\footnotetext{
${ }^{1}$ Department of Polymer Chemistry, Graduate School of Engineering, Kyoto University, Katsura, Nishikyo-ku, Kyoto 615-8510, Japan. Correspondence and requests for materials should be addressed to M.S. (email: sawamoto@star.polym.kyoto-u.ac.jp).
} 
T he marriage of supramolecular/organic chemistry and polymer chemistry is a promising strategy for the efficient and selective synthesis of designed materials ${ }^{1-3}$. It often involves template molecules that non-covalently or covalently interact with substrates, to induce a specific conformation, in which reactive sites and substrates are oriented suitably for chemical bond formation. For example, such a template-directed synthesis ${ }^{4-10}$ utilizing supramolecular interaction or molecular recognition is quite effective for intramolecular cyclization by bringing reactive sites close to one another. Metal $\left(\mathrm{M}^{+}\right)$or ammonium $\left(\mathrm{R}_{\mathrm{n}} \mathrm{NH}_{4-\mathrm{n}}^{+}\right)$cations are often employed as templates for selective cyclization of poly(ethylene glycol) (PEG)-containing substrates into crown ether derivatives $s^{4,8}$ or interlocked molecules (rotaxanes and catenanes) ${ }^{5-7,9,10}$, typically combined with metathesis reactions. Templates assist not only the selective production of such supramolecular materials ${ }^{4-10}$ but also the precision control of the primary structure of polymers ${ }^{1-18}$. For example, we and other groups have recently developed template-assisted precision control of tacticity ${ }^{15}$ and monomer sequence $e^{16-18}$ in conjunction with metal-catalysed living radical polymerization $^{19-22}$.

Cyclopolymerization $^{23-36}$ is a chain polymerization of bifunctional monomers via alternating propagation process of intramolecular cyclization and intermolecular addition, to give soluble linear polymers consisting of 'in-chain' cyclic structures. This strategy affords direct and quantitative incorporation of cyclic units into polymers as repeating units, in sharp contrast to the polymerization of monomers bearing a cyclic pendent group $^{37}$ or the postfunctionalization of linear polymers ${ }^{38}$. With the in-chain multiple cyclic units, cyclopolymers potentially show unique functions, for example, polymeric (pseudo-)crown ethers recognize particular cations in a way different from their monomeric counterparts ${ }^{25,32,39}$. The key for selective vinyl-type cyclopolymerization is to bring the two olefins in a bifunctional monomer to close proximity for effective intramolecular cyclization. This suppresses intermolecular propagation with only one of the two alkene units into pendent olefin-bearing polymers; otherwise the dangling olefin further causes intermolecular crosslinking of polymers to give insoluble gels and/or branched polymers ${ }^{40-43}$. So far, cyclopolymers with relatively large in-chain rings (at most 20-membered rings) generally required the elaborate design of bifunctional monomers that bring two olefins close, typically through a rigid spacer ${ }^{29-32}$, except for counterparts with small five- or six-membered rings from 1,6-dienes and 1,6-diynes ${ }^{33-36}$.

Herein, we report cation template-assisted controlled radical cyclopolymerization of poly(ethylene glycol) dimethacrylates (PEGnDMA: $\mathrm{CH}_{2}=\mathrm{C}\left(\mathrm{CH}_{3}\right) \mathrm{COO}-\left(\mathrm{CH}_{2} \mathrm{CH}_{2} \mathrm{O}\right)_{n}-\mathrm{C}(\mathrm{O}) \mathrm{C}\left(\mathrm{CH}_{3}\right)=$ $\left.\mathrm{CH}_{2}, n=4-8\right)$ as a novel, one-pot and versatile strategy to selectively produce, so-called polymeric pseudo-crown ethers, cyclopolymers with large in-chain PEG rings (each with 19- to 30membered ether units, 13-100 rings per chain) for efficient and unique cation recognition (Fig. 1). The polymer synthesis is achieved through the specific interaction of the PEG unit with the metal cation. PEGnDMA is treated with metal salts $\left(\mathrm{M}^{+} \mathrm{X}^{-}\right)$in polymerization to assume the pseudo-cyclic conformation $\left(\mathrm{PEG} n \mathrm{DMA}-\mathrm{M}^{+}\right)$via dynamic equilibrium, where the two intramolecular vinyl groups are brought adjacent and are thereby suitably positioned for cycloaddition. The cyclization of PEG $n$ DMA with a template was effective up to 30 -membered 'in-chain' PEG ring based on eight flexible oxyethyrene units. Typically, ruthenium-catalysed polymerization of $\mathrm{K}^{+}$-template PEG6DMA directly leads to water-soluble linear polymers with narrow molecular weight distributions $\left(M_{\mathrm{w}} / M_{\mathrm{n}} \sim 1.2\right)$ and large 24-membered in-chain cyclic PEG units (>97\%), without gels or unreacted dangling olefin. The cyclic PEG units efficiently work as nanocavities to interact with alkali metal cations, 1:1 per cyclic unit for $\mathrm{Rb}^{+}, \mathrm{K}^{+}, \mathrm{Na}^{+}$and $\mathrm{Li}^{+}$or $1: 2$ for $\mathrm{Cs}^{+}$, and selectively
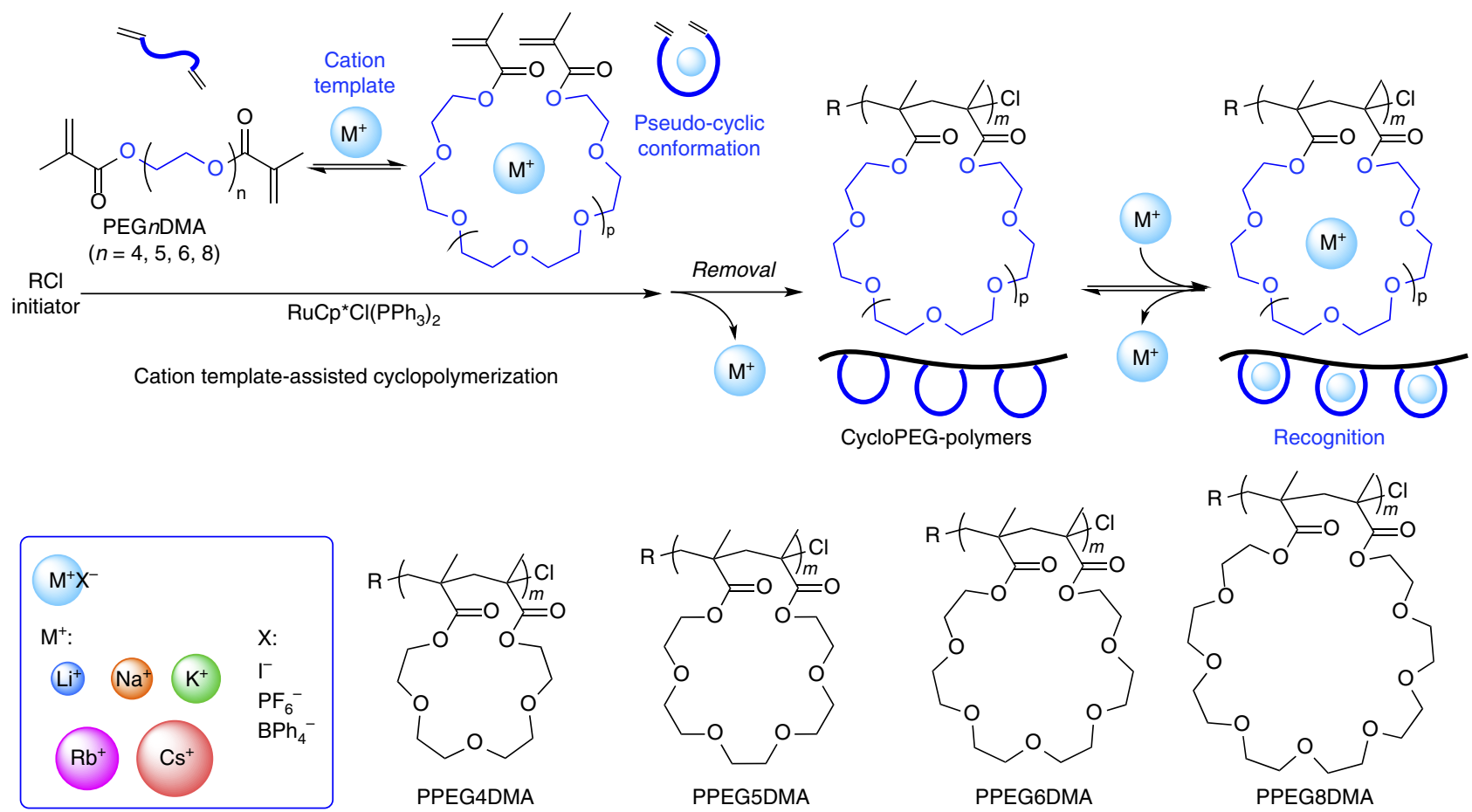

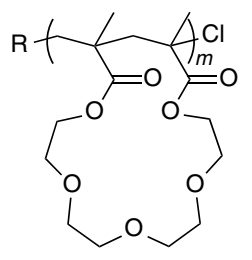

PPEG4DMA

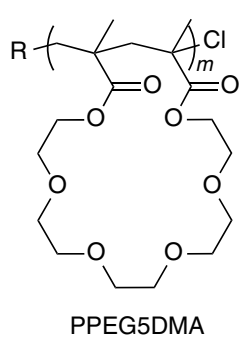

PPEG5DMA

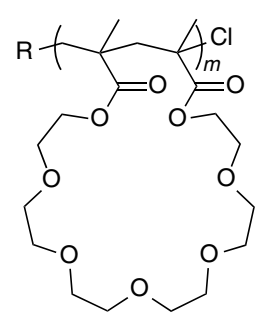

PPEG6DMA

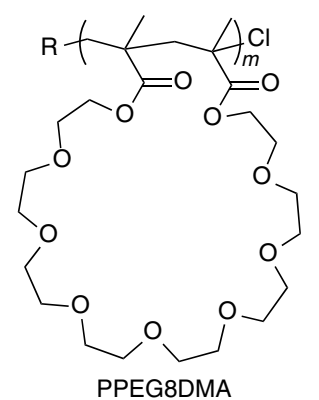

Figure 1 | Cation template-assisted cyclopolymerization for polymeric pseudo-crown ethers. PEGnDMA efficiently interacts with metal cations to in situ form pseudo-cyclic conformation with the adjacent location of the two olefins, which induces the alternating propagation process of intramolecular cyclization and intermolecular addition to selectively give linear polymers comprising large in-chain cyclic PEG rings (up to 30 membered). Thus, cyclic PEG polymers behave as polymeric pseudo-crown ethers to perform unique cation recognition dependent on the ring size. 
recognize $\mathrm{Na}^{+}$over $\mathrm{Li}^{+}$or $\mathrm{Bu}_{4} \mathrm{~N}^{+}$and $\mathrm{K}^{+}$over $\mathrm{Na}^{+}$under competitive conditions. To our knowledge, this is the first example to apply cation templates for selective and efficient cyclopolymerization of divinyl monomers carrying a long, flexible spacer via the alternating propagation of intramolecular cyclization and intermolecular addition into cyclopolymers containing multiple and large in-chain PEG rings, in sharp contrast to conventional template-directed intramolecular cyclization for crown etherbased supramolecular materials ${ }^{4-10}$. It should be noted that this template-mediated cyclopolymerization is an efficient, one-pot and selective chemical transformation from common reagents with simple templates to functional cyclopolymers.

\section{Results}

Cation template monomers. PEGnDMAs, dimethacrylates carrying a PEG spacer unit $\left[-\left(\mathrm{CH}_{2} \mathrm{CH}_{2} \mathrm{O}\right)_{n^{-}}\right]$of a well-defined degree of polymerization $(n=4,5,6,8)$ were employed as monomers for cation template-assisted cyclopolymerization. The interaction between PEG $n$ DMA and metal cations was first evaluated (Fig. 2, Supplementary Fig. S1-S3 and Supplementary Table S1). In general, 18-crown-6, a cyclic crown ether consisting of six ethylene oxide units, efficiently recognizes potassium cation $\left(\mathrm{K}^{+}\right)$because the inner pore is best fit in size for $\mathrm{K}^{+}$(ref. 4). PEG6DMA was thus mixed with $\mathrm{KPF}_{6}$ in acetone- $d_{6} /$ cyclohexanone $(1 / 1, \mathrm{v} / \mathrm{v})$ to analyse its interaction with $\mathrm{K}^{+}$by proton nuclear magnetic resonance spectroscopy $\left({ }^{1} \mathrm{H}\right.$ NMR) (Fig. 2a,b). The protons $\left(c, d^{\prime}\right.$, and $d$ ) assignable to the PEG segment shifted to downfield by +0.04 p.p.m., larger than the accompanying shift in the chain-end methacrylate groups $(a, b:<\sim 0.01$ p.p.m.), suggesting that the PEG spacer efficiently interacts with $\mathrm{K}^{+}$. The stoichiometry of the interaction was 1:1 (one cation per PEG6DMA), as determined by Job's method based on the chemical shift change of the PEG proton (peak $c$ ) and the molar fraction of PEG units $(\chi)$ : [PEG6DMA] $/\left[\mathrm{KPF}_{6}\right]=10 / 0-10 / 1$, $[\mathrm{PEG} 6 \mathrm{DMA}]+\left[\mathrm{KPF}_{6}\right]=10 \mathrm{mM}$ (Fig. 2c); the plot showed a maximum at $\chi=0.5$. The association constant $\left(K_{\mathrm{a}}\right)$ was estimated as $\sim 70 \mathrm{M}^{-1}$ by ${ }^{1} \mathrm{H}$ NMR titration experiment of PEG6DMA with $\mathrm{K}^{+}$(Supplementary Figs S2 and S3 and Supplementary Table S1). Similarly, PEG5DMA and PEG8DMA also captured $\mathrm{K}^{+}$via 1:1 interaction, whereas PEG4DMA was totally ineffective (Fig. $2 c$ ), suggesting that $\mathrm{K}^{+}$was suited for PEG $n$ DMAs carrying 5-8 ethylene oxide units. In addition, PEG6DMA recognized $\mathrm{K}^{+}$ more efficiently than $\mathrm{Na}^{+}$and $\mathrm{Li}^{+}$(NaI: $K_{\mathrm{a}}=\sim 30 \mathrm{M}^{-1}$; LiI: no specific interaction, Supplementary Table S1).

The local mobility of PEG6DMA was further evaluated with longitudinal relaxation time $\left(T_{1}\right)$ of the carbons $(a-d)$ in the presence of $\mathrm{KPF}_{6}$ by ${ }^{13} \mathrm{C}$ NMR ([PEG6DMA]/[ $\left[\mathrm{KPF}_{6}\right]=1 / 2$; Fig. 2d, Supplementary Fig. S4 and Supplementary Table S2). For all the carbons, $T_{1} \mathrm{~s}$ with $\mathrm{K}^{+}\left[T_{1}\left(\mathrm{~K}^{+}\right) \mathrm{s}\right]$ were smaller than those without $\mathrm{K}^{+}\left(T_{1} \mathrm{~s}\right)$. As plotted in Fig. $2 \mathrm{~d}$, the ratio $\left[T_{1}\left(\mathrm{~K}^{+}\right) / T_{1} \mathrm{~s}\right]$ for PEG units ( $c$ and $d$ ) was much smaller than that for methacrylate moieties $(a$ and $b$ ), demonstrating that the PEG segment predominantly binds $\mathrm{K}^{+}$. The same conclusion was also supported by ultraviolet-visible analysis (Supplementary Fig. S5).

Template-assisted cyclopolymerization. Cation template-assisted cyclopolymerization of PEG6DMA was carried out in
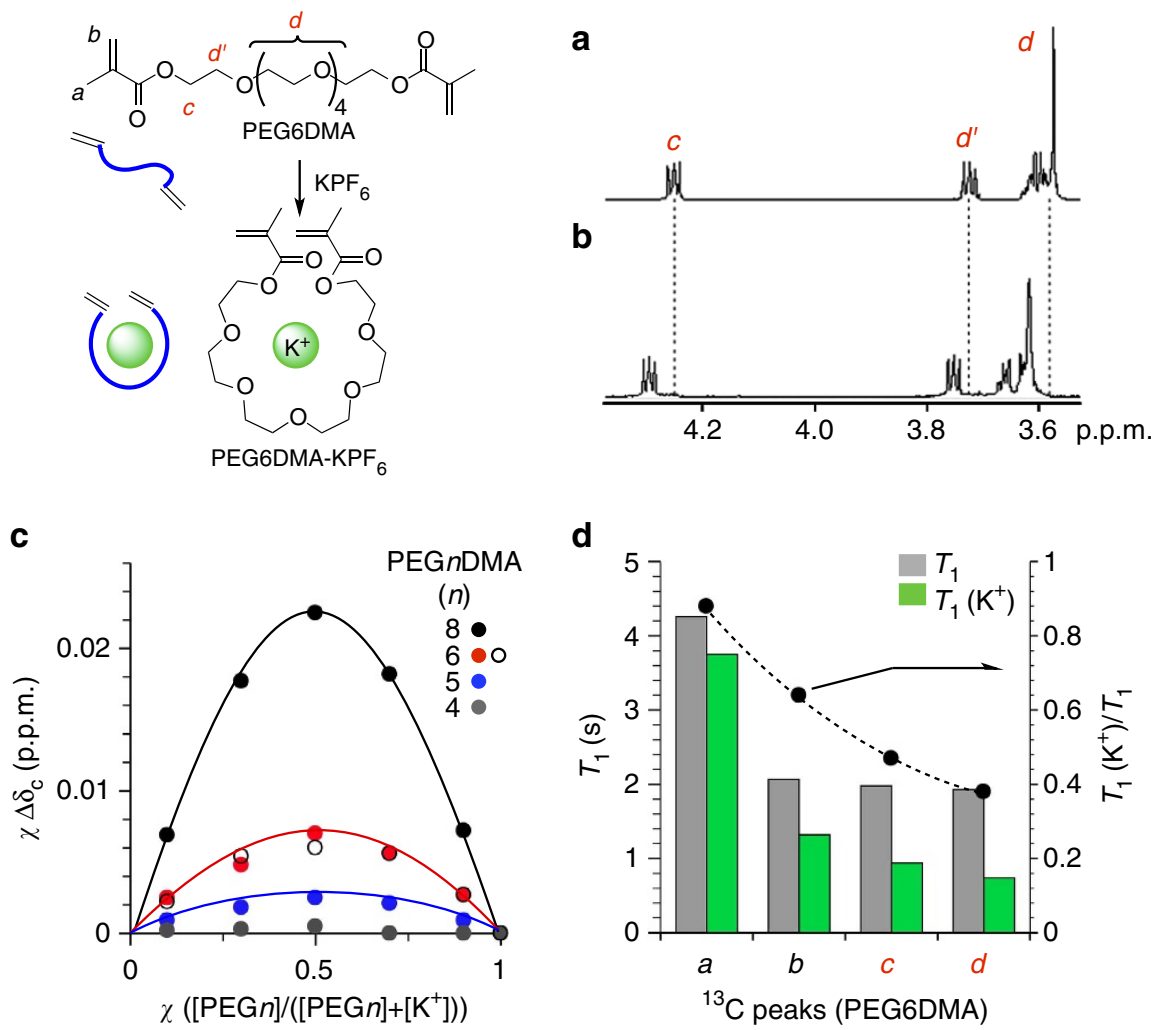

Figure 2 | Interaction of PEGnDMA with a $\mathbf{K}^{+}$template. ${ }^{1} \mathrm{H}$ NMR spectra of PEG6DMA (a) and PEG6DMA with $\mathrm{KPF}_{6}(\mathbf{b})$ in acetone- $d_{6} / \mathrm{cycl}$ lohexanone $(1 / 1, \mathrm{~V} / \mathrm{V})$ at $30^{\circ} \mathrm{C}$. The proton signals of the ethylene oxide unit on PEG6DMA shifted to downfield in the presence of $\mathrm{KPF}_{6}$. (c) Job plots were obtained from ${ }^{1} \mathrm{H}$ NMR measurements of PEGnDMAs with KI (filled circle: $n=4$ (grey), 5 (blue), 6 (red), 8 (black)) or $\mathrm{KPF}_{6}(n=6:$ open black circle) $\left([\mathrm{PEGnDMA}]_{0}+\left[\mathrm{K}^{+}\right]_{0}=10 \mathrm{mM}\right)$. PEGnDMAs efficiently interact with $\mathrm{K}+$ via 1:1 per PEG unit, except for PEG4DMA. (d) Longitudinal relaxation time $\left(T_{1}\right)$ measurements of the carbons for PEG6DMA (grey bar) and PEG6DMA with $\mathrm{KPF}_{6}$ (green bar) by ${ }^{13} \mathrm{C} \mathrm{NMR.} T_{1}\left(\mathrm{~K}^{+}\right) \mathrm{s}$ for PEG6DMA with KPF 6 turned smaller than those for PEG6DMA alone, meaning the decreasing mobility of PEG6DMA with $\mathrm{K}^{+}$. Importantly, efficient interaction of the PEG segment (peaks: $c, d$ ) with $\mathrm{K}^{+}$was supported by the ratio $\left(T_{1}\left(\mathrm{~K}^{+}\right) / T_{1}\right.$ : filled circle) for the PEG smaller than that for methacrylates (peaks: $\left.a, b\right)$. 
conjunction with a ruthenium catalytic system $\left[\mathrm{RuCp}{ }^{\star} \mathrm{Cl}\left(\mathrm{PPh}_{3}\right)_{2} / n\right.$ $\left.\mathrm{Bu}_{3} \mathrm{~N}\right]$ and a chloride initiator $\left[\mathrm{H}-(\mathrm{MMA})_{2}-\mathrm{Cl}\right]^{44}$ in cyclohexanone at $40^{\circ} \mathrm{C}$. Following the cation recognition data, the bifunctional monomer was mixed with $\mathrm{K}^{+}$at $1 / 1$ molar ratio in cyclohexanone to in situ transform a pseudo-cyclic monomer with $\mathrm{K}^{+}$template. Without further isolation of the complex, the mixture was directly polymerized under dilute conditions $\left([\mathrm{PEG} 6 \mathrm{DMA}]_{0}=\right.$ 25-100 mM) (Fig. 3, Table 1 and Supplementary Fig. S6). The targeted degree of polymerization $\left(D P=[\mathrm{PEG} 6 \mathrm{DMA}]_{0} /\right.$
$\left.\left[\mathrm{H}-(\mathrm{MMA})_{2}-\mathrm{Cl}\right]_{0}\right)$ was set at $12.5-100$, that is, the number of 'in-chain' cyclic units per polymer $=12.5,25,50$ and 100. The polymerization proceeded smoothly and homogeneously in high yield $(\sim 90 \%$ conversion in $30-56 \mathrm{~h})$ without any gelation, independent of the targeted DP. The number-average molecular weight of products increased with increasing conversion and was proportional to the targeted $D P \mathrm{~s}\left(M_{\mathrm{n}}=7,500-31,100 ; M_{\mathrm{w}} / M_{\mathrm{n}}=\right.$ 1.1-1.5; by size-exclusion chromatography (SEC); Fig. 3a). Thus, this ruthenium-mediated cyclopolymerization with metal cation a

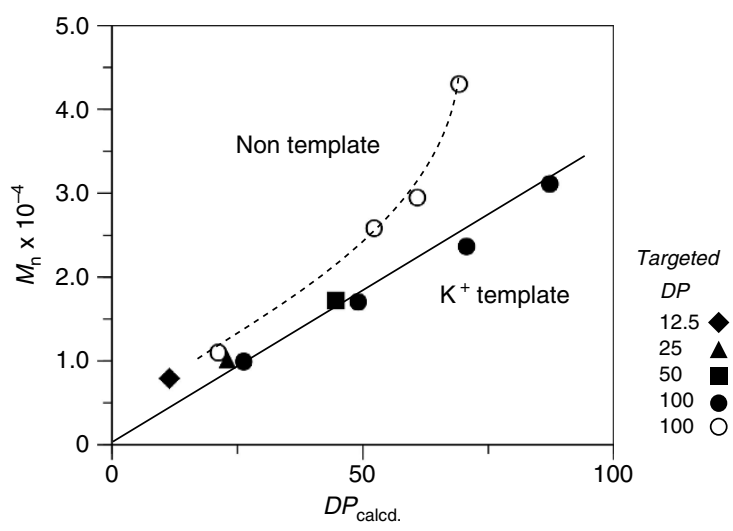

b

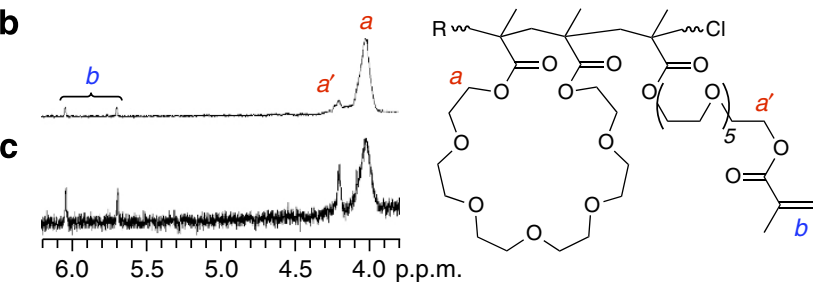

d
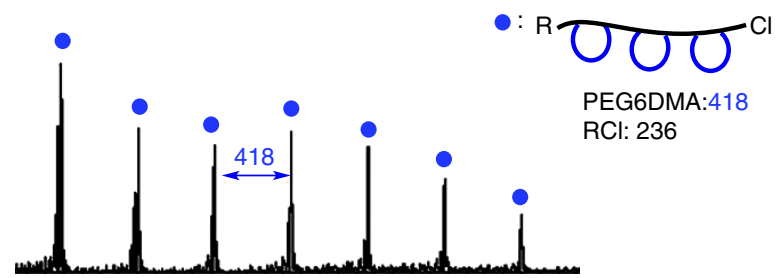

e

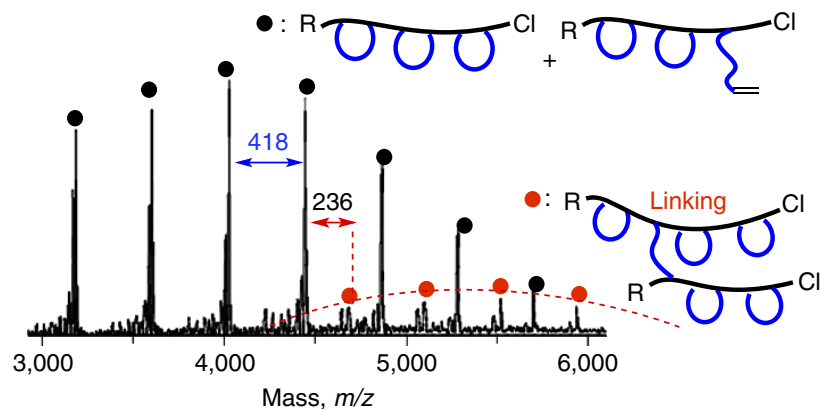

Figure $3 \mid \mathbf{K}^{+}$template-assisted cyclopolymerization of PEG6DMA. (a) Number-averaged molecular weight as a function of calculated degree of polymerization $\left(D P_{\text {calcd. }}\right.$ ): $[\mathrm{PEG} 6 \mathrm{DMA}] /\left[\mathrm{KPF}_{6}\right] /\left[\mathrm{H}-(\mathrm{MMA})_{2}-\mathrm{Cl}(\mathrm{RCl})\right] /\left[\mathrm{RuCp}^{\star} \mathrm{Cl}\left(\mathrm{PPh}_{3}\right)_{2}\right] /\left[\mathrm{n}-\mathrm{Bu}_{3} \mathrm{~N}\right]=25-100 / 0-100 / 2.0,1.0 / 0.5 / 20 \mathrm{mM}$ in cyclohexanone at $40{ }^{\circ} \mathrm{C} .{ }^{1} \mathrm{H}$ NMR $(\mathbf{b}, \mathbf{c})$ and MALDI-TOF-MS (d,e $)$ spectra of initial PPEG6DMA samples (Targeted DP=13) obtained with a KPF 6 template $(\mathbf{b}, \mathbf{d})$ and without the template $(\mathbf{c}, \mathbf{e})$. The $\mathrm{K}^{+}$template-assisted polymerization of PEG6DMA smoothly and selectively gave linear PPEG6DMA with high cyclization efficiency ( $>97 \%$, (d): filled blue circle), whereas the direct polymerization of PEG6DMA induced intermolecular linking reaction of polymer chains to lead to high-molecular weight products including dangling olefins ( $20 \%$, (e): filled black and red circles).

Table 1 | K ${ }^{+}$template-assisted cyclopolymerization of PEGnDMA.

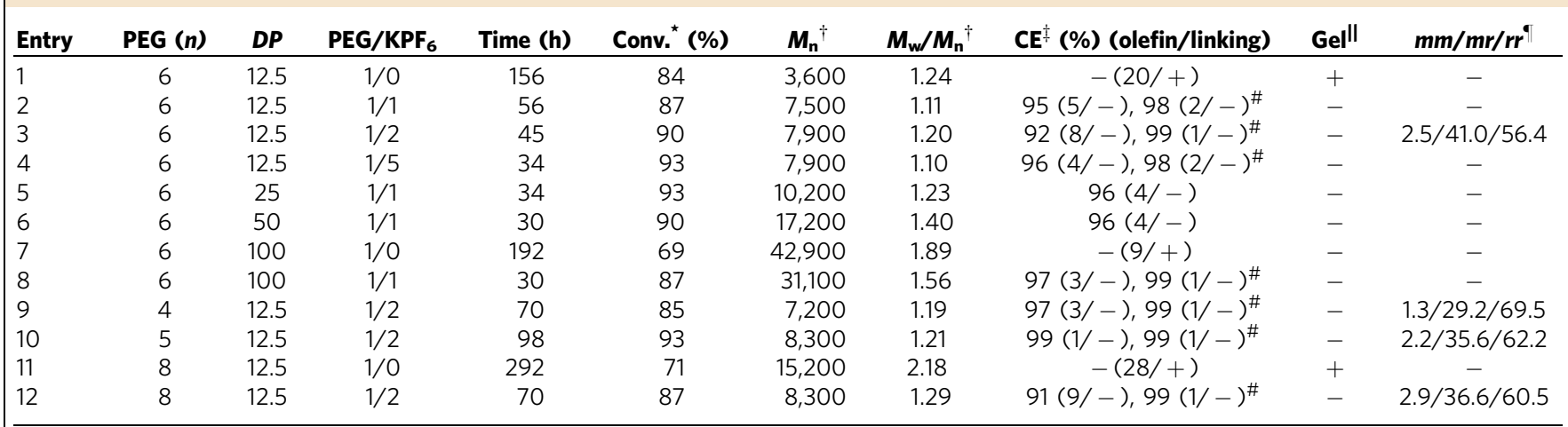

$[P E G n D M A]_{0} /\left[\mathrm{KPF}_{6}\right]_{0} /\left[\mathrm{H}-(\mathrm{MMA})_{2}-\mathrm{Cl}(\mathrm{RCl})\right]_{0} /\left[\mathrm{RuCp}^{*} \mathrm{Cl}\left(\mathrm{PPh}_{3}\right)_{2}\right]_{0} /\left[n-\mathrm{Bu}_{3} \mathrm{~N}\right]_{0}=25-100 / 0-125 / 1.0$ or 2.0/0.5/20 mM in cyclohexanone at 40 ${ }^{\circ} \mathrm{C} ; \mathrm{DP}=[\mathrm{PEGnDMA}]_{0} /[\mathrm{RCl}]_{0}=25 / 2,50 / 2,100 / 2$, $100 / 1(\mathrm{mM} / \mathrm{mM})=12.5,25,50,100$.

${ }^{*}$ Conversion (Conv.) (\%): Determined by ${ }^{1} \mathrm{H}$ NMR with tetralin as an internal standard.

$\dagger M_{n}$ and $M_{w} / M_{n}$ of final products: determined by SEC in N, $\mathrm{N}^{\prime}$-dimethylformamide (DMF) (10 mM LiBr) with PMMA standard calibration.

${ }^{\dagger}$ Cyclization efficiency (CE), olefin (pendant olefin content), and linking (intermolecular linking of chains) for initial products (conv. $=<30 \%$ ). Olefin content: determined by ${ }^{1} \mathrm{H}$ NMR with the following equation: $100\left[4 b /\left(a+a^{\prime}\right)\right](\%)$ (peaks: assigned in Fig. 3b,c). Linking: confirmed by MALDI-TOF-MS and/or SEC (high molecular weight) (+: observed; -: not observed). CE for non-linking samples was calculated from the following: CE $(\%)=100-$ olefin.

IIInsoluble gel formed in reaction mixtures ( + : observed; - : not observed).

- Stereoregularity of products was determined by ${ }^{13} \mathrm{C}$ NMR.

${ }^{\#} \mathrm{CE}$, olefin (pendant olefin content), and linking (intermolecular linking) for final products. 
templates was efficiently controlled to lead to linear polymers. Such a fine control was also maintained with excess cation over the monomer $\left([\mathrm{PEG} 6 \mathrm{DMA}]_{0} /\left[\mathrm{KPF}_{6}\right]_{0}=1 / 1,1 / 2,1 / 5 ; D P=12.5\right.$; $\left.M_{\mathrm{w}} / M_{\mathrm{n}}=<1.2\right)$. In contrast, direct polymerization of PEG6DMA in a cation-free system (entries 1,7) was retarded and resulted in high-molecular weight products with bimodal distribution $\left(M_{\mathrm{w}} /\right.$ $M_{\mathrm{n}}$ : $\left.\sim 2.0\right)$ and/or some gels, suggesting intermolecular crosslinking of linear chains.

Microscopic structures of products were analysed by matrixassisted laser desorption ionization time-of-flight mass spectrometry (MALDI-TOF-MS) and ${ }^{1} \mathrm{H}$ NMR spectroscopy, to determine the intramolecular cyclization efficiency $(\mathrm{CE})^{18}$. Figure $3 \mathrm{~d}$ shows a typical MALDI spectrum of poly(PEG6DMA) obtained with $\mathrm{K}^{+}$at the initial stage (targeted $D P=12.5 ; \sim 30 \%$ conversion in entry 2). The sample exhibited a single series of peaks (blue filled circle), regularly separated by the molar mass of the monomer (418.5). The absolute mass of each peak was equal to that expected for the PEG6DMA polymer capped with one initiator fragment $\left[\mathrm{H}-(\mathrm{MMA})_{2}-\right]$ at the $\alpha$-end and one chlorine at the $\omega$-end ( $c f . m / e$ for $\left.\mathrm{H}-(\mathrm{MMA})_{2}-+\mathrm{Cl}: 236.7\right)$, plus a sodium ion from externally added salt for ionization. The products showed ${ }^{1} \mathrm{H}$ NMR signals of the methacrylate backbone $\left(\mathrm{CH}_{3}\right.$ : 0.7-1.2 p.p.m.; $-\mathrm{CH}_{2}-$ : 1.4-2.0 p.p.m.) and the cyclized PEG units $\left(-\mathrm{CH}_{2} \mathrm{CH}_{2} \mathrm{O}-\right.$ : $\quad 3.4-3.7$ p.p.m.; $\quad-\mathrm{COOCH}_{2} \mathrm{CH}_{2} \mathrm{O}-\quad\left(a+a^{\prime}\right.$ : 4.0-4.2 p.p.m.) but virtually without olefin signals (b: 5.7, 6.0 p.p.m.) (Fig. 3b and Supplementary Fig. S7). From the signal intensity ratio $b /\left(a+a^{\prime}\right)$, the dangling (unreacted) olefin content was estimated as $4.9 \%$ for an initial sample (conversion $\sim 30 \%$, Fig. 3b) and $2.4 \%$ for a final sample (conversion $87 \%$, Supplementary Fig. S7). The decrease with conversion suggests that the observed olefin might be located at the $\omega$-terminal unit, where one methacrylate in the monomer is consumed by intermolecular propagation, whereas another stands by for intramolecular cyclization.

These results indicate that at high CE ( $>97 \%)$, that is, nearly without intermolecular crosslinking, almost all methacrylate units of PEG6DMA are cyclopolymerized into linear cyclopolymers with a large 24-membered 'in-chain' cyclic PEG unit. Separate experiments also showed that CE was as high as 95-99\%, invariably independent of the template feed ([PEG6DMA $]_{0} /$ $\left.\left[\mathrm{KPF}_{6}\right]_{0}=1 / 1-1 / 5\right)$ and targeted $D P\left([\mathrm{PEG} 6 \mathrm{DMA}]_{0} /[\text { initiator }]_{0}=\right.$ $12.5-100)$.

On the contrary, samples prepared without $\mathrm{K}^{+}$showed two series of mass peaks from the initial stage of the polymerization ( $\sim 30 \%$ conversion in entry 1 ; Fig. $3 \mathrm{e}$ ). In addition to a series of cyclopoly(PEG6DMA) with one $\alpha$-end initiator fragment (black filled circles), another series in the higher-molecular-weight region (red filled circles) was consistent with polymers carrying two initiator fragments indicative of intermolecular crosslinking (coupling) of two chains. These samples showed large ${ }^{1} \mathrm{H}$ NMR signals of dangling olefins $(b)$ and adjacent methylene units $\left(a^{\prime}\right)$ (Fig. 3c), in which, without cation template, $\sim 20 \%$ monomer units were not intramolecularly cyclized even under diluted monomer conditions $(25 \mathrm{mM})$.

We further examined cyclopolymerization with other templates $\left(\mathrm{LiPF}_{6}, \mathrm{NaPF}_{6}\right.$ and $\left.\mathrm{CsBPh}_{4}\right)$ and/or PEG dimethacrylate monomers of different spacer length (PEG $n$ DMA; $n=4,5,8$ ) (Table 1, Supplementary Table S3 and Supplementary Fig. S8). For PEG6DMA, $\mathrm{KPF}_{6}\left(\mathrm{~K}^{+}\right)$was the most effective template; CE: $85 \%\left(\mathrm{LiPF}_{6}\right), 93 \%\left(\mathrm{NaPF}_{6}\right), 95 \%\left(\mathrm{KPF}_{6}\right), 85 \%\left(\mathrm{CsBPh}_{4}\right) ;<80 \%$ (no template). Random and block copolymerizations with methyl methacrylate (MMA) were also possible (random: MMA/ PEG6DMA $=25 / 13$ or $75 / 13 ; M_{\mathrm{w}} / M_{\mathrm{n}}=1.2$; block (from MMA): MMA/PEG6DMA $=100 / 13 ; \quad M_{\mathrm{w}} / M_{\mathrm{n}}=1.3$ ) (Supplementary Figs S9 and S10). The $\mathrm{K}^{+}$template was also applicable to PEG5DMA and PEG8DMA to give linear cyclopolymers carrying
21- and 30-membered in-chain PEG rings, respectively (cf. 24membered rings with PEG6DMA). In contrast, the cyclopolymerization of PEG4DMA occurred in fairly high CE independent of templates (even without a template cation), because the restricted conformation from the relatively short spacer renders the two vinyl groups intramolecularly close to each other without the assistance of a template 28,43. $^{2}$.

The template effect on the conformation of PEGnDMA/K ${ }^{+}$ pairs was confirmed in dynamics calculation (software: Schrödinger MacroModel 9.5; duration $10^{6} \mathrm{fs} ; 300 \mathrm{~K}$ ) (Supplementary Figs S11 and S12). For example, the inter-olefin distance in PEG6DMA in the presence of $\mathrm{K}^{+}$was in the range of 3.0-7.0 ( $>99 \%$ probability) and $4.7 \AA\left(d_{\text {avg }}\right)$ on average, whereas without $\mathrm{K}^{+}$the distance fluctuated more widely from 3.0 to $10 \AA$ or beyond ( $>10 \AA$ in $\sim 50 \%$ probability; $d_{\text {avg }}=8.7 \AA$ ). Similar simulation results were obtained for PEG5DMA and PEG8DMA. Additionally, $d_{\text {avg }}$ for PEG6DMA decreased as a function of cations: template free $(8.7 \AA)>\mathrm{Cs}^{+}(7.9 \AA)>\mathrm{Na}^{+}(5.2 \AA)>\mathrm{K}^{+}$ $(4.7 \AA)$. Note that the CE in cyclopolymerization increased in the opposite order, demonstrating that the shorter $d_{\text {avg }}$ is the more favored cyclopropagation.

Properties. Owing to some steric requirement on cyclopropagation and/or the resulting cyclic repeat units, PPEG $n$ DMAs exhibited stereoregularity different from that of the linear pendant counterparts (PPEGnMA) ${ }^{18}$. Analysed by ${ }^{1} \mathrm{H}$ and ${ }^{13} \mathrm{C}$ NMR (Table 1, Supplementary Fig. S7), PPEG $n$ DMAs $(n=5,6,8)$ were more heterotactic than PPEGnMA $(n=4,8.5)(\mathrm{mm} / \mathrm{mr} /$ $r r=2.2 / 35.6 / 62.2$ (PEG5DMA), 2.5/41.0/56.4 (PEG6DMA), 2.9/ 36.6/60.5 (PEG8DMA), 2.1/30.9/67.0 (PEG4MA), 1.9/29.9/68.2 (PEG8.5MA)). Although the stereoregularity for PPEGnMA was independent of the pendant length, that for PPEGnDMAs was dependent on the ring size $(n)$.

Cyclopolymerization expectedly reduced the thermal mobility of the spacer PEG units. Determined by ${ }^{13} \mathrm{C} \mathrm{NMR}$, spin-lattice relaxation time $\left(T_{1}\right)$ of the PEG spacer carbons in PPEG6DMA was $0.51 \mathrm{~s}$, much shorter than those for the monomer $(1.93 \mathrm{~s})$ and for the linear pendants in PPEG8.5MA (1.68 s) (Supplementary Table S4). Within the cyclopolymers PPEGnDMA, $T_{1}$ decreased with decreasing number of oxyethylene units $(n): T_{1}(n)=0.48$ (5), 0.51 (6), 0.68 (8); the shorter the spacer (the smaller ring size), the more limited the thermal mobility. The lowered mobility also supports the formation of cyclopolymers with inchain' polyether rings.

Because of the hydrophilic and thermosensitive PEG units, cyclopolymers of PEG6DMA and PEG8DMA were soluble in water at room temperature (r.t.) but underwent reversible, hysteresis-free phase transition in a narrow temperature range where the lower critical solution temperature (LCST) was 35 and $50{ }^{\circ} \mathrm{C}$, respectively (Supplementary Fig. S13). The LCST for PPEG6DMA was between those for non-cyclic counterparts from PEG2MA $\left(\sim 26^{\circ} \mathrm{C}\right)$ and PEG3MA $\left(\sim 52^{\circ} \mathrm{C}\right)^{45,46}$. PPEG6DMA might provide attractive thermosensitive amphiphilic biomaterials with LCST close to the human body temperature.

Ion recognition. Given their consecutively placed in-chain crown ether units, recognition of metal cations was examined for PPEGnDMAs obtained with the $\mathrm{K}^{+}$template (Fig. 4, Supplementary Figs S14-S18 and Supplementary Table S5). Thus, interaction of PPEG6DMA $\left(D P=12.5 ; M_{\mathrm{n}}=7,900\right)$ with alkali metal salts (LiI, NaI, KI, $\mathrm{KPF}_{6}$ and RbI; separately mixed with the polymer) was followed by ${ }^{1} \mathrm{H}$ NMR spectroscopy in an acetone$d_{6} /$ cyclohexanone mixed solvents $(1 / 1, \mathrm{v} / \mathrm{v})$ at $30^{\circ} \mathrm{C}$ (Fig. $4 \mathrm{a}$ ). Exposure to their cations induced downfield shifts in the PEG protons, indicative of cation encapsulation into the cyclic 


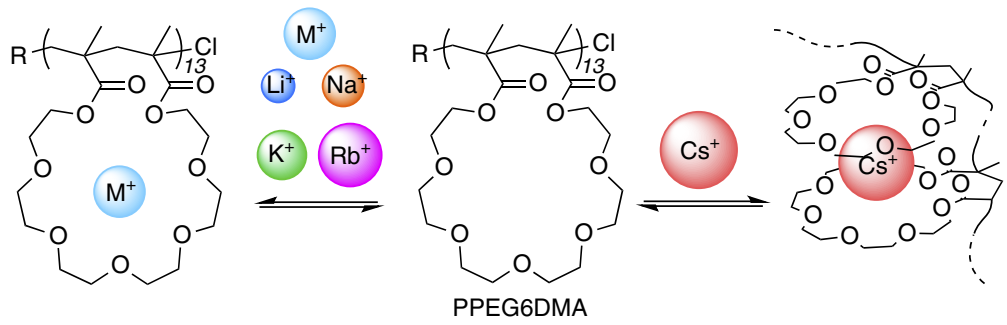

a

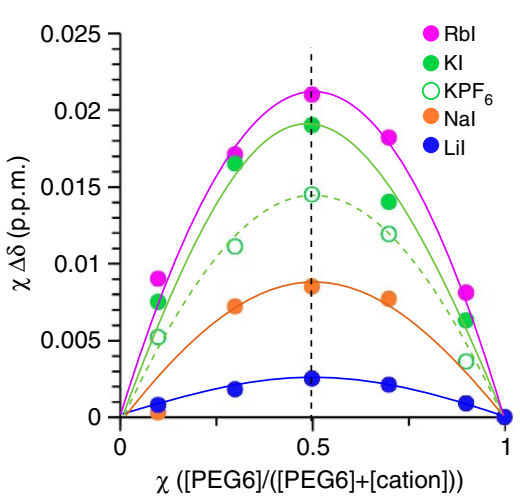

b

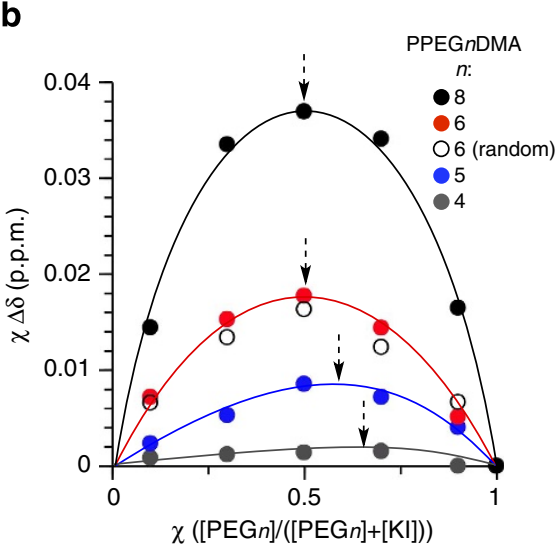

C

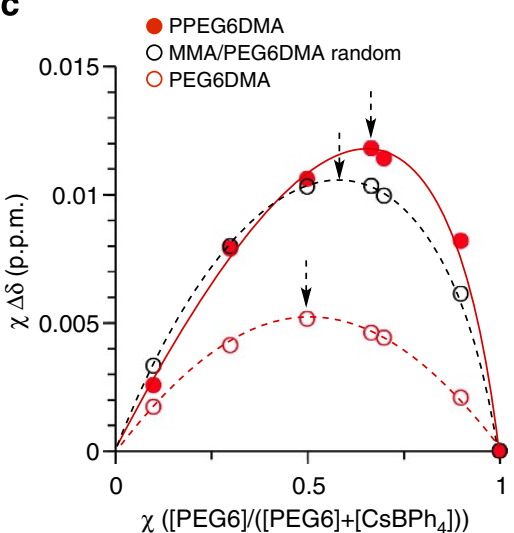

Figure 4 | Cation recognition with PPEGnDMA. Job plots were obtained from ${ }^{1} \mathrm{H}$ NMR measurements of PPEGnDMA $(n=4-8)$ with metal cations in acetone- $d_{6} /$ cyclohexanone $(1 / 1)$ at $30^{\circ} \mathrm{C}$ ([cyclic PEG units on PPEGDMA $\left.]_{0}+[\text { cation }]_{0}=10 \mathrm{mM}\right)$. (a) Job plots for PPEG6DMA with various metal cations ( $\mathrm{Lil}, \mathrm{Nal}, \mathrm{KPF}_{6}, \mathrm{Kl}, \mathrm{Rbl}$ ) support 1:1 recognition of their cations per cycloPEG unit. (b) Effects of spacer length ( $n$ ) of PPEGnDMA (homopolymer: filled circles; a MMA/PEG6DMA (75/13) random copolymer: open circle) on KI recognition (dash arrow: peak top). (c) $\mathrm{CsBPh}_{4}$ recognition with PPEG6DMA (filled red circle), a MMA/PEG6DMA (75/13) random copolymer (open black circle), PEG6DMA (open red circle) (dash arrow: peak top). PPEGnDMA efficiently recognized a $\mathrm{Cs}^{+}$per two neighbouring cyclic PEG units due to the local high density.

backbone cavity. The symmetrical Job plots peaked at $\chi=0.5$ (molar fraction of the ring unit) demonstrated a 1:1 stoichiometeric interaction between a cation guest and an in-chain ring host. The cyclopolymer exhibited a stronger cation affinity than its monomer, judged from the association constant by ${ }^{1} \mathrm{H}$ NMR $\left(K_{\mathrm{a}}\left(\mathrm{M}^{-1}\right): \sim 130\right.$ versus $\sim 70$ with $\mathrm{KPF}_{6} ; \sim 30$ versus $\sim 0$ (no interaction) with LiI). Equally important, $\mathrm{K}^{+}$fitted to the cyclopolymer more efficiently than $\mathrm{Li}^{+}\left(K_{\mathrm{a}}\left(\mathrm{M}^{-1}\right): \sim 130\left(\mathrm{~K}^{+}\right)\right.$ versus $\sim 30\left(\mathrm{Li}^{+}\right)$) owing to the ring size suitable for $\mathrm{K}^{+}$. The 1:1 cation binding also occurred in an MMA/PEG6DMA random copolymer (75/13 ratio in $D P$ ) consisting of the same cycloPEG units and the $K_{\mathrm{a}}\left(\sim 140 \mathrm{M}^{-1}\right)$ was similar to that with a PEG6DMA homopolymer. This indicates that each in-chain ring captures $\mathrm{K}^{+}$independently without interfering effects with the neighbouring units. The thermal mobility $\left(T_{1}\right)$ of cycloPEG units decreased on $\mathrm{K}^{+}$recognition (Supplementary Table S4).

However, the $\mathrm{K}^{+}$recognition by PPEGnDMA was dependent on the ring size $(n)$ (Fig. $4 \mathrm{~b})$. The stoichiometry $\left(\mathrm{K}^{+}\right.$:cycloPEG unit) changed from 1:1 to $1: 2$ as $n$ decreased from 6 to 4 , judged from the fact that the Job-plot maximum shifted from $\chi=0.5$ to 0.66 . PPEG8DMA with larger in-chain rings captured $\mathrm{K}^{+}$ in 1:1 stoichiometry four times more efficiently than PPEG6DMA $\left(K_{\mathrm{a}} \quad\left(\mathrm{M}^{-1}\right)=\sim 460 \quad(\right.$ PPEG8DMA $), \quad \sim 130 \quad($ PPEG6DMA $\left.)\right)$, though the 30-membered ring from PEG8DMA seemed too large for $\mathrm{K}^{+}$at first glance. Uniquely, the binding with PPEG8DMA preferentially occurred via the middle oxyethylene units $\left(d:-\left(\mathrm{CH}_{2} \mathrm{CH}_{2} \mathrm{O}\right)_{n^{-}}\right)$rather than via those adjacent to the ester linkages $\left(c\right.$ : $\left.-{ }^{-} \mathrm{COOCH}{ }_{2} \mathrm{CH}_{2} \mathrm{O}-\right)$, as the $K_{\mathrm{a}}$ for $d$ is larger than the $K_{\mathrm{a}}$ for $c\left(K_{\mathrm{a}}\left(\mathrm{M}^{-1}\right)=\sim 110(c)\right.$ versus $\left.\sim 460(d)\right)$. This is because the 30 -membered ring is spacious and flexible enough to mobilize some of the middle ether units, assuming a conformation better fit for the cation. In contrast, PPEG6DMA with rigid 24membered rings apparently needs all the ring units (both middle (d) and ester-bound (c)) to capture $\mathrm{K}^{+}$, as indicated by virtually no difference among their binding constants. The association constant of PPEGnDMA to $\mathrm{K}^{+}$(maximum: $K_{\mathrm{a}}\left(\mathrm{M}^{-1}\right)=\sim 460$ ) was smaller than that of crown ether derivatives with similar ring size under identical conditions (that is, dibenzo-21-crown-7-ether to $\left.\mathrm{K}^{+}: K_{\mathrm{a}}\left(\mathrm{M}^{-1}\right)=\sim 2.0 \times 10^{4}\right)$ probably owing to strained conformation of the in-chain cyclized PEG units.

Recognition of a caesium cation $\left(\mathrm{CsBPh}_{4}\right)$ was further examined with cycloPEG homopolymers (PPEG6DMA, PPEG8DMA), an MMA/PEG6DMA (75/13) random copolymer and their monomers (Fig. 4c, Supplementary Fig. S18). Their homopolymers bound one $\mathrm{Cs}^{+}$with two cycloPEG units (peak maximum in Job plots: $\chi=0.66$ ), whereas their monomers did $\mathrm{Cs}^{+}$via $1: 1$ stoichiometry $\left(\mathrm{Cs}^{+}\right.$: cycloPEG) as well as the other cations $\left(\mathrm{Na}^{+}, \mathrm{K}^{+}, \mathrm{Rb}^{+}\right.$; Supplementary Fig. S1). Such specific $1: 2$ recognition $\left(\mathrm{Cs}^{+}\right.$:cycloPEG) was independent of counter anion and solvents (CsI: recognized with two cycloPEG in $\mathrm{CD}_{3} \mathrm{OD}$ ). In contrast, the random copolymer competitively involved both 1:1 recognition and 1:2 counterpart $\left(\mathrm{Cs}^{+}\right.$: cycloPEG), where the peak maximum of the Job plot was at $\sim 0.6$ between 0.66 and 0.5 . 18-Crown- 6 in turn selectively showed 1:1 recognition. Thus, the unique 1:2 recognition for $\mathrm{Cs}^{+}$ is attributed to the local high concentration of cycloPEG units per chain. Confirmed by dynamic light scattering, PPEG6DMA in the presence of $\mathrm{K}^{+}$or $\mathrm{Cs}^{+}$had hydrodynamic radius $\left(R_{\mathrm{h}}\right)$ almost identical to PPEG6DMA alone $\left(R_{\mathrm{h}}=6.3 \mathrm{~nm}\left(\mathrm{~K}^{+}\right.\right.$or $\left.\mathrm{Cs}^{+}\right)$, $7.9 \mathrm{~nm}$ (non cation) in acetone), indicating that cycloPEG polymers intramolecularly grasped $\mathrm{Cs}^{+}$with the two neighbouring cycloPEG units within a single chain.

Selective and competitive ion recognition. The efficiency and selectivity in the cation recognition by PPEG6DMA was further 


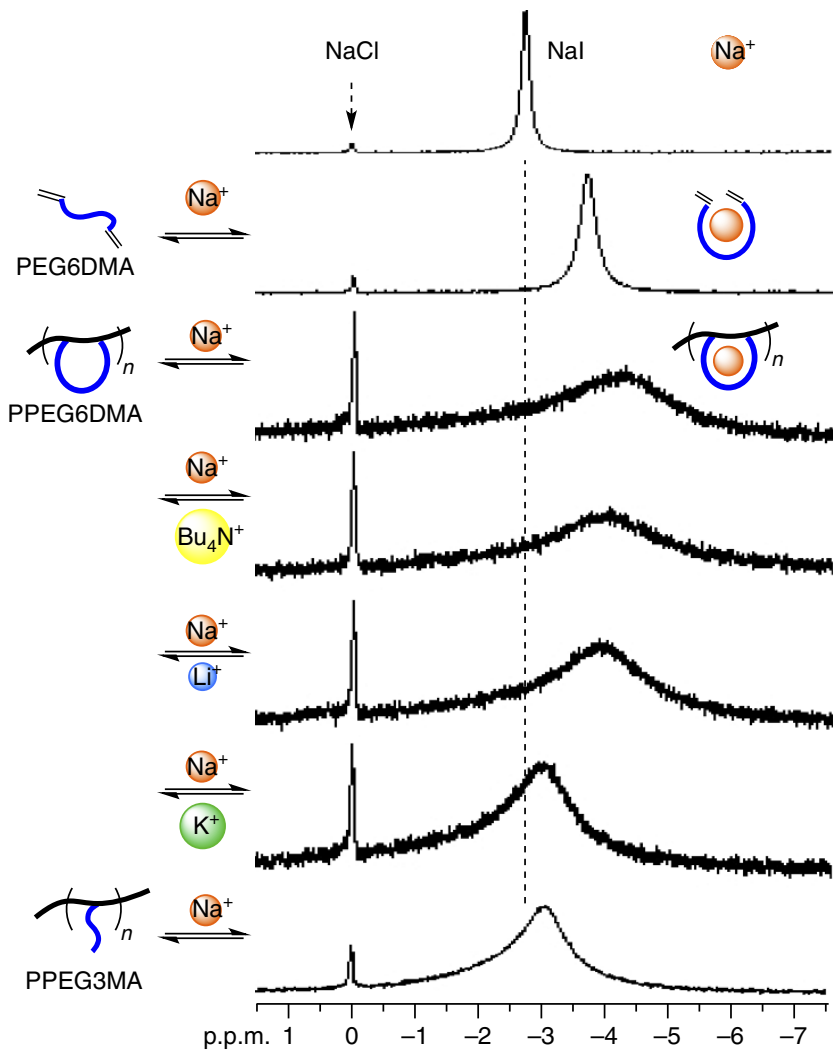

Figure 5 | Competitive cation recognition with PPEG6DMA. ${ }^{23} \mathrm{Na}$ NMR measurements of Nal with PPEG6DMA in the presence of other cations $\left(\mathrm{Bu}_{4} \mathrm{NI}, \mathrm{Lil}, \mathrm{KI}\right)$ were conducted in acetone- $d_{6} /$ cyclohexanone $(1 / 1, \mathrm{v} / \mathrm{v})$ at $30^{\circ} \mathrm{C}$. Owing to the 'in-chain' cyclic PEG structure, PPEG6DMA recognized Nal more efficiently than PEG6DMA (monomer) and poly(triethylene glycol methyl ether methacrylate) (PPEG3MA: linear pendant). Additionally, PPEG6DMA performed $\mathrm{Na}^{+}$recognition selective over $\mathrm{Bu}_{4} \mathrm{~N}^{+}$or $\mathrm{Li}^{+}$, and $\mathrm{K}^{+}$recognition over $\mathrm{Na}^{+}$.

evaluated in competitive recognition. Thus, in cyclohexanone/ acetone- $d_{6}(1 / 1, \mathrm{v} / \mathrm{v})$, the polymer was mixed with an equimolar mixture of $\mathrm{Na}$ and another alkali metal cation, and the selectivity was evaluated in monitoring the sodium guest by ${ }^{23} \mathrm{Na} \mathrm{NMR}$ spectroscopy (Fig. 5); obviously, ${ }^{1} \mathrm{H}$ or ${ }^{13} \mathrm{C}$ NMR is totally useless in this analysis, because there was little difference in the chemical shift between cyclic PEG units with $\mathrm{Na}$ and with another cation. This method will also provide evidence for recognition not from the host (PEG by NMR) but from the guest (cation).

In the presence of PPEG6DMA, the $\mathrm{Na}$ signal of $\mathrm{NaI}$ shifted upfield by $\Delta \delta=-1.53$ p.p.m. and broadened (half width: $350 \mathrm{~Hz}$ from $19.8 \mathrm{~Hz}$ (polymer-free salt)). The peak shift and broadening was larger than those with the monomer $(-0.96$ p.p.m. and $40 \mathrm{~Hz})$ and with PPEG3MA (a linear pendant counterpart to PPEG6DMA: -0.34 p.p.m. and $135 \mathrm{~Hz}$ ), again demonstrating the efficient cation binding by ${ }^{23} \mathrm{Na}$ NMR.

More importantly, PPEG6DMA selectively recognized $\mathrm{Na}^{+}$ over $\mathrm{Li}^{+}$or $\mathrm{Bu}_{4} \mathrm{~N}^{+}$and in turn $\operatorname{did} \mathrm{K}^{+}$over $\mathrm{Na}^{+}$in competitive experiments where an equimolar mixture of the probe and another cation was exposed to the cyclopolymer. The upfield shift and broadening for the sodium signal of $\mathrm{NaI}$ with PPEG6DMA were still maintained in the presence of $\mathrm{Bu}_{4} \mathrm{NI}$ and LiI. However, KI made the sodium signal shifting to downfield (close to original position) again and narrow. This implies that the presence of competing cations does not seriously interfere with the recognition of a preferred cation and that the cation selectivity in PPEG6DMA increases in the order $\mathrm{Bu}_{4} \mathrm{~N}<\mathrm{Li}<$ $\mathrm{Na}<\mathrm{K}$. In addition, the in-chain cyclic PEG units are essential for the selective recognition, as PPEG3MA turned out poorly selective in cation recognition (Supplementary Fig. S19).

\section{Discussion}

Cyclopolymerization of divinyl monomers for linear polymers containing in-chain cyclic structures essentially undergoes an alternating propagation process of intramolecular cyclization and intermolecular addition, in which the efficient intramolecular cyclization is a key step to prevent the intermolecular crosslinking of polymer chains. In cation template-assisted cyclopolymerization, a potassium cation $\left(\mathrm{K}^{+}\right)$effectively interacts with PEGbearing dimethacrylates, PEG $n$ DMA $(n=5-8)$ to transform the random conformation into the pseudo-cyclized counterpart. As a result, the two vinyl groups come close to be suitable for intramolecular cyclization, which is also supported by molecular dynamics calculation. Owing to high tolerance to polar functional groups including metal cations ${ }^{19,20}$, a ruthenium catalytic system efficiently induces controlled radical cyclopolymerization of PEG $n$ DMA in the presence of a potassium cation to directly give linear polymers (PPEG $n$ DMA) bearing large (19-30 membered) in-chain cyclic PEG rings with controlled molecular weight.

The resulting PPEGnDMAs further work as unique nanocavities to recognize metal cations, more efficiently and selectively than their linear pendant counterparts and an original monomer. In the present design, the binding constant to metal cations is smaller than that with corresponding crown ethers. This is probably because cyclized PEG rings in PPEGnDMAs have steric strain and/or irregular conformation originating from the illcontrolled stereoregularity, though PPEG $n$ DMAs $(n=5-8)$ obtained with a potassium template are more heterotactic than linear counterparts (PPEGMAs). Thus, development of stereoregular cyclopolymerization of $\mathrm{PEG} n \mathrm{DMA}$ would be important for resolving that issue; such a polymerization system could produce cycloPEG polymers with highly regulated ring conformation to induce cooperative recognition of cationic compounds more efficiently and selectively compared with conventional crown ethers. In addition, cation template-assisted polymerization is quite versatile to afford various primary structures from simple cyclopolymers to random and block copolymers containing cyclized PEG $n$ DMA units. In the future, cycloPEG-bearing microgel star polymers might be useful as efficient and selective scavengers to extract (or remove) metal cations from solution, because microgel star polymers potentially behave as nanocapsules to capture molecules and can be easily recovered from solution by modulating the arm species ${ }^{41}$.

In conclusion, we have successfully developed cation templatemediated, controlled radical cyclopolymerization of PEG spacerbearing dimethacrylates, PEG $n$ DMA $(n=4-8)$, for polymeric pseudo-crown ethers performing unique cation recognition. The synergistic marriage of supramolecular chemistry and polymer chemistry opens a new efficient strategy to create well-defined functional cyclopolymers from common reagents with simple template molecules. Multi-control of primary structures and/or tailor-made design of three-dimensional architectures would further advance cycloPEG-based polymers as novel functional macromolecules to innovate on molecular recognition.

\section{Methods}

Materials. Triethylene glycol monomethyl ether (Aldrich, purity $>95 \%$ ), tetraethylene glycol (TCI, purity >95\%), pentaethylene glycol (TCI, purity $>95 \%$ ), hexaethylene glycol (Aldrich, purity $>97 \%$ ), octaethylene glycol (Wako, purity $>97 \%$ ), tetrahydrofuran ( Wako; dehydrated), diethyl ether (Wako, purity $>99.5 \%$ ), sodium sulphate (Wako, purity $>99 \%$ ) and $25 \%$ ammonia solution 
(Wako) were used as received. Methacryloyl chloride (TCI, purity $>80 \%$ ) and triethylamine (TCI, purity $>99 \%$ ) were purified by distillation before use.

MMA (TCI; purity >99\%) was dried overnight over calcium chloride and purified by double distillation under reduced pressure from calcium hydride before use. Poly(ethylene glycol) dimethacrylate (PEGnDMA: $n=\left[-\left(\mathrm{CH}_{2} \mathrm{CH}_{2} \mathrm{O}\right)-\right] /$ $[\mathrm{PEGnDMA}]=4,5,6,8)$ was synthesized as shown below. Triethylene glycol methyl ether methacrylate (PEG3MA) was prepared according to the literature ${ }^{45}$. Poly(ethylene glycol) methyl ether methacrylate (PEGnMA: $M_{n}=475(n=8.5)$; $M_{\mathrm{n}}=300(n=4)$; Aldrich) was purified by an inhibitor remover column (product no.: 311332 , Aldrich) and was degassed by vacuum-argon purge cycles before use. Ethyl $\alpha$-chlorophenylacetate (ECPA: Aldrich; purity $>97 \%$ ) was purified by distillation under reduced pressure before use. $\mathrm{H}-(\mathrm{MMA})_{2}-\mathrm{Cl}$ was prepared according to the literature ${ }^{44}$. $\mathrm{RuCp}{ }^{*} \mathrm{Cl}\left(\mathrm{PPh}_{3}\right)_{2}\left(\mathrm{Cp}^{*}\right.$ : pentamethylcyclopentadienyl, Aldrich, purity $>97 \%$ ) was used as received and was handled in a grove box under a moisture- and oxygen-free argon atmosphere $\left(\mathrm{H}_{2} \mathrm{O}<1\right.$ p.p.m., $\mathrm{O}_{2}<1$ p.p.m. $)$. $n$ - $\mathrm{Bu}_{3} \mathrm{~N}$ (TCI, purity $>98 \%$ ) was degassed by vacuum-argon purge cycles before use. Tetralin (1,2,3,4-tetrahydronaphthalene) (Kisida Chemical, purity $>98 \%$ ), as an internal standard to check the conversion of PEGn(D)MA by ${ }^{1} \mathrm{H}$ NMR, was dried over calcium chloride overnight and distilled twice from calcium hydride. Cyclohexanone (Wako, purity >99\%) was dried on molecular sieves 4A (Wako) and degassed by vacuum-argon purge cycles before use. Methanol (Wako, purity $>99.8 \%$ ) and regenerated cellulose dialysis membranes (Spectra/Por 7; molecular weight cut off (MWCO) 1,000) for polymer purification were used as received.

Lithium iodide (LiI: Aldrich; purity $>99 \%$ ), sodium iodide (NaI: Aldrich; purity $>99.9 \%$ ), potassium iodide (KI: Wako; purity $>99 \%$ ), potassium hexafluorophosphate $\left(\mathrm{KPF}_{6}\right.$ : Aldrich; purity $\left.>98 \%\right)$, rubidium iodide (RbI: Aldrich; purity $>99.9 \%$ ), caesium iodide (CsI: Aldrich; purity $>99.9 \%$ ), caesium tetraphenylborate $\left(\mathrm{CsBPh}_{4}\right.$ : Aldrich; purity $\left.>98 \%\right)$, 18-crown-6 (Wako, purity $>98 \%$ ), dibenzo-21-crown-7-ether (TCI, purity $>96 \%$ ) and acetone- $d_{6}(\mathrm{CIL})$ were used as received.

Monomer synthesis. A typical procedure for PEG6DMA was given: in a 200-ml round-bottomed flask filled with argon, methacryloyl chloride $(94.6 \mathrm{mmol}, 9.1 \mathrm{ml})$ was added dropwise to a solution of hexaethylene glycol $(31.5 \mathrm{mmol}, 10 \mathrm{ml})$ and triethylamine $(94.6 \mathrm{mmol}, 6.3 \mathrm{ml})$ in dry tetrahydrofuran $(70 \mathrm{ml})$ at $0^{\circ} \mathrm{C}$. The reaction mixture was stirred at $0{ }^{\circ} \mathrm{C}$ for $2 \mathrm{~h}$ and at $25^{\circ} \mathrm{C}$ for an additional $22 \mathrm{~h}$, and then evaporated under reduced pressure. The concentrated crude was diluted with diethyl ether $(150 \mathrm{ml})$ and washed with water $(150 \mathrm{ml})$. The aqueous layer was separated and further extracted with diethyl ether $(150 \mathrm{ml})$. The combined ether solution was washed with $200 \mathrm{ml}$ of $25 \%$ ammonia water three times and with $200 \mathrm{ml}$ of distilled water once, and was dried on sodium sulphate overnight. Into the purified ether solution of PEG6DMA, dried cyclohexanone was added. The solution was then evaporated under reduced pressure to remove the ether to give cyclohexanone solution of PEG6DMA for cyclopolymerization. ${ }^{1} \mathrm{H}$ NMR $\left(500 \mathrm{MHz}\right.$, acetone- $d_{6}$, r.t., $\delta=2.05$ p.p.m. (acetone)): $\delta 6.08$ (m, olefin, $\left.2 \mathrm{H}\right), 5.62$ (m, olefin, $2 \mathrm{H}), 4.24\left(\mathrm{t}, J=4.8 \mathrm{~Hz}, 4 \mathrm{H},-\mathrm{COOCH}_{2} \mathrm{CH}_{2} \mathrm{O}-\right), 3.71(\mathrm{t}, J=4.8 \mathrm{~Hz}, 4 \mathrm{H}$, $\left.-\mathrm{COOCH}_{2} \mathrm{CH}_{2} \mathrm{O}-\right), 3.62-3.56\left(\mathrm{~m}, 16 \mathrm{H},-\mathrm{OCH}_{2} \mathrm{CH}_{2} \mathrm{O}-\right), 1.92\left(\mathrm{~m}, 6 \mathrm{H},-\mathrm{CCH}_{3}\right) .{ }^{13} \mathrm{C}$ NMR (125 MHz, acetone- $d_{6}$, r.t., $\delta=206.5$ p.p.m. (acetone)): $\delta 168.0,138.0,126.3$, $72.0,70.3,65.3,19.2$. Electrospray ionization mass spectrometry $m / z\left([\mathrm{M}+\mathrm{Na}]^{+}\right)$: calcd. for $\mathrm{C}_{20} \mathrm{H}_{34} \mathrm{O}_{9} \mathrm{Na}$ 441.2, found 441.2. See Supplementary Methods for synthesis and characterization of other monomers.

Polymerization. Cation template-assisted living radical cyclopolymerization of PEGnDMA $(n=4-8)$ was carried out by the syringe technique under argon in baked glass tubes equipped with a three-way stopcock. PEGnDMA was pre-mixed with $\mathrm{KPF}_{6}$ in cyclohexanone at a predetermined ratio $\left([\mathrm{PEG} n \mathrm{DMA}] /\left[\mathrm{KPF}_{6}\right]=1 / 1-\right.$ $1 / 5)$ to give a cyclohexanone solution of PEG6DMA interacting with $\mathrm{KPF}_{6}$. A typical procedure for PPEG6DMA $(D P=12.5)$ was given: $\mathrm{RuCp}{ }^{*} \mathrm{Cl}\left(\mathrm{PPh}_{3}\right)_{2}$ $(0.005 \mathrm{mmol}, 4.0 \mathrm{mg})$ was placed in a $30-\mathrm{ml}$ glass tube. Into the tube, cyclohexanone $(8.7 \mathrm{ml})$, tetralin $(0.1 \mathrm{ml})$, a $400-\mathrm{mM}$ toluene solution of $n-\mathrm{Bu}_{3} \mathrm{~N}(0.2 \mathrm{mmol}$, $0.5 \mathrm{ml}$ ), a $789 \mathrm{mM}$ cyclohexanone solution of PEG6DMA with $\mathrm{KPF}_{6}$ ([PEG6DMA $]=0.25 \mathrm{mmol},\left[\mathrm{KPF}_{6}\right]=0.5 \mathrm{mmol}, 0.32 \mathrm{ml}$ ), and a $57.6 \mathrm{mM}$ toluene solution of $\mathrm{H}$-(MMA $)_{2}-\mathrm{Cl}(0.02 \mathrm{mmol}, 0.35 \mathrm{ml})$ were added sequentially in this order at $25^{\circ} \mathrm{C}$ under argon. The tube containing the mixture (total volume: $10 \mathrm{ml}$ ) was placed in an oil bath at $40^{\circ} \mathrm{C}$. In predetermined intervals, a small portion of the reaction mixture was sampled and cooled to $-78^{\circ} \mathrm{C}$ to terminate the reaction. The conversion of PEG6DMA was then determined by ${ }^{1} \mathrm{H}$ NMR measurement with an internal standard (tetralin) in $\mathrm{CDCl}_{3}$ at r.t. After $56 \mathrm{~h}$ (conversion $=87 \%$ ), the quenched reaction mixture was evaporated to dryness under reduced pressure. The resulting crude was first fractionated by preparative SEC in N, $\mathrm{N}^{\prime}$-dimethylformamide (DMF) and then dialysed in water with a regenerated cellulose membrane (Spectra/Por 7; MWCO 1,000) for 5 days. The inner solution was evaporated to dryness under reduced pressure to give PPEG6DMA. SEC (DMF, $0.01 \mathrm{M} \mathrm{LiBr}$ ): $M_{\mathrm{n}}=7900 \mathrm{~g} \mathrm{~mol}^{-1} ; M_{\mathrm{w}} / M_{\mathrm{n}}=1.20 .{ }^{1} \mathrm{H}$ NMR [ $500 \mathrm{MHz}, \mathrm{CDCl}_{3}, \delta=7.26$ $\left.\left(\mathrm{CHCl}_{3}\right)\right]$ : $\delta 6.2,5.6$ (olefin), 4.2-4.0 (- $\left.\mathrm{COOCH}_{2} \mathrm{CH}_{2} \mathrm{O}-\right), 3.8-3.5\left(-\mathrm{OCH}_{2} \mathrm{CH}_{2} \mathrm{O}-\right)$, $2.1-1.3\left(-\mathrm{CH}_{2} \mathrm{CCH}_{3}\right), 1.3-0.8\left(-\mathrm{CCH}_{3}\right) . \mathrm{CE}=\sim 99 \% .{ }^{13} \mathrm{C}$ NMR $\left[125 \mathrm{MHz}, \mathrm{CDCl}_{3}\right.$, $\left.\delta=77.0\left(\mathrm{CHCl}_{3}\right)\right]: \delta$ 178.2-175.5 $(\mathrm{C}=\mathrm{O}), 71.1-70.2\left(-\mathrm{OCH}_{2} \mathrm{CH}_{2} \mathrm{O}-\right), 68.8-68.4$ (- $\left.\mathrm{COOCH}_{2} \mathrm{CH}_{2} \mathrm{O}-\right)$, 64.6-63.8 (- $\left.\mathrm{COOCH}_{2} \mathrm{CH}_{2} \mathrm{O}-\right)$, 55.5-52.0 (- $\left.\mathrm{CH}_{2} \mathrm{C}\left(\mathrm{CH}_{3}\right) \mathrm{CO}-\right)$,
45.6-44.5 (- $\left.\mathrm{CH}_{2} \mathrm{C}\left(\mathrm{CH}_{3}\right) \mathrm{CO}-\right), 22.6-16.0\left(-\mathrm{CH}_{3}\right) . \mathrm{mm} / \mathrm{mr} / \mathrm{rr}=2.5 / 41.0 / 56.4$. See Supplementary Methods for the synthesis and characterization of other polymers.

Characterization. The molecular weight distribution, $M_{\mathrm{n}}$ and $M_{\mathrm{w}} / M_{\mathrm{n}}$ ratios of polymers were measured by SEC in DMF containing $10 \mathrm{mM} \mathrm{LiBr}$ at $40^{\circ} \mathrm{C}$ (flow rate: $1 \mathrm{ml} \mathrm{min}^{-1}$ ) on three linear-type polystyrene gel columns (Shodex KF-805L; exclusion limit $=4 \times 10^{6}$; particle size $=10 \mu \mathrm{m}$; pore size $=5,000 \AA$; $0.8 \mathrm{~cm}$ i.d. $\times 30 \mathrm{~cm}$ ) that were connected to a Jasco PU-2080 precision pump, a Jasco RI2031 refractive index detector and a Jasco UV-2075 ultraviolet/visible detector set at $270 \mathrm{~nm}$. The columns were calibrated against ten standard poly(MMA) samples (Polymer Laboratories; $M_{\mathrm{n}}=1,000-12,00,000 ; M_{\mathrm{w}} / M_{\mathrm{n}}=1.06-1.22$ ). Polymer samples to analyse the structure and investigate the cation recognition were fractionated by preparative SEC (column: Shodex K-2003; exclusion limit $=7 \times 10^{4}$; particle size $=6 \mu \mathrm{m}$; pore size $=500 \AA ̊ 2.0 \mathrm{~cm}$ i.d. $\times 30 \mathrm{~cm}$, eluent: DMF) and dialysed with regenerated cellulose membranes in methanol.

${ }^{1} \mathrm{H},{ }^{13} \mathrm{C}$ and ${ }^{23} \mathrm{Na}$ NMR spectra were recorded in acetone- $d_{6}$, DMSO- $d_{6}$, and $\mathrm{CDCl}_{2}$ at $30^{\circ} \mathrm{C}$ on a JEOL JNM-LA500 spectrometer, operating at $500\left({ }^{1} \mathrm{H}\right), 125$ $\left({ }^{13} \mathrm{C}\right)$ and $132\left({ }^{23} \mathrm{Na}\right) \mathrm{MHz}$, respectively. MALDI-TOF-MS analysis was performed on a Shimadzu AXIMA-CFR instrument equipped with $1.2 \mathrm{~m}$ linear flight tubes and a 337-nm nitrogen laser with dithranol (1,8,9-anthracenetriol) as an ionizing matrix and sodium trifluoroacetate as a cationizing agent. Electrospray ionization mass spectrometry was performed on Waters Quattro micro API. Dynamic light scattering was measured on Otsuka Photal ELSZ-0 equipped with a semiconductor laser (wavelength $=658 \mathrm{~nm}$ ) at $25^{\circ} \mathrm{C}$. The measuring angle was $165^{\circ}$, and the data was analysed by the CONTIN fitting method.

Ultraviolet-visible spectra were obtained from Shimadzu UV-1,800 in $\mathrm{H}_{2} \mathrm{O}$ or $\mathrm{CH}_{2} \mathrm{ClCH}_{2} \mathrm{Cl}$ at r.t. (optical path length $=1.0 \mathrm{~cm}$ ). The cloud points of the polymers in water were determined by the transmittance of aqueous solution of polymers and monitored at $660 \mathrm{~nm}$ by changing the solution temperature between 20 and $80^{\circ} \mathrm{C}$ (optical path length $=1.0 \mathrm{~cm}$; heating rate $=1{ }^{\circ} \mathrm{C} \mathrm{min}{ }^{-1}$; cooling rate $=-1{ }^{\circ} \mathrm{C} \min ^{-1}$ ) on Shimadzu UV-1800.

\section{References}

1. Meeuwissen, J. \& Reek, J. N. H. Supramolecular catalysis beyond enzyme mimics. Nat. Chem. 2, 615-621 (2010).

2. Suzuki, K., Sato, S. \& Fujita, M. Template synthesis of precisely monodisperse silica nanoparticles within self-assembled organometallic spheres. Nat. Chem. 2, 25-29 (2010).

3. McHale, R., Patterson, J. P., Zetterlund, P. B. \& O’Reilly, R. K. Biomimetic radical polymerization via cooperative assembly of segregating templates. Nat Chem. 4, 491-497 (2012).

4. Pedersen, C. J. Cyclic polyethers and their complexes with metal salts. J. Am. Chem. Soc. 89, 7017-7036 (1967).

5. Meyer, C. D., Joiner, C. S. \& Stoddart, J. F. Template-directed synthesis employing reversible imine bond formation. Chem. Soc. Rev. 36, 1705-1723 (2007).

6. Crowley, J. D., Goldup, S. M., Lee, A.-L., Leigh, D. A. \& McBurney, R. T. Active metal template synthesis of rotaxanes, catenanes and molecular shuttles. Chem. Soc. Rev. 38, 1530-1541 (2009).

7. Zhang, M., Zhu, K. \& Huang, F. Improved complexation of paraquat derivatives by the formation of crown ether-based cryptands. Chem. Commun. 46, 8131-8141 (2010).

8. Marsella, M. J., Maynard, H. D. \& Grubbs, R. H. Template-directed ring-closing metathesis: synthesis and polymerization of unsaturated crown ether analogs. Angew. Chem. Int. Ed. 36, 1101-1103 (1997).

9. Cantrill, S. J. et al. A. Template-directed olefin cross metathesis. Org. Lett. 7, 4213-4216 (2005).

10. Belowich, M. E. et al. Positive cooperativity in the template-directed synthesis of monodisperse macromolecules. J. Am. Chem. Soc. 134, 5243-5261 (2012).

11. Tan, Y. Y. The synthesis of polymers by template polymerization. Prog. Polym. Sci. 19, 561-588 (1994).

12. Połowinski, S. Template polymerization and co-polymerization. Prog. Polym. Sci. 27, 537-577 (2002).

13. Serizawa, T., Hamada, K. \& Akashi, M. Polymerization within a molecular-scale stereoregular template. Nature 429, 52-55 (2004).

14. South, C. R. \& Weck, M. Template-enhanced ring-opening metathesis polymerization. Macromolecules 40, 1386-1394 (2007).

15. Wan, D., Satoh, K. \& Kamigaito, M. Triple hydrogen bonding for stereospecific radical polymerization of a DAD monomer and simultaneous control of tacticity and molecular weight. Macromolecules 39, 6882-6886 (2006).

16. Ida, S., Terashima, T., Ouchi, M. \& Sawamoto, M. Selective radical addition with a designed heterobifunctional halide: a primary study toward sequencecontrolled polymerization upon template effect. J. Am. Chem. Soc. 131, 10808-10809 (2009).

17. Ida, S., Ouchi, M. \& Sawamoto, M. Designer template initiator for sequence regulated polymerization: system design for substrate-selective metal-catalyzed radical addition and living radical polymerization. Macromol. Rapid Commun. 32, 209-214 (2009). 
18. Hibi, Y., Tokuoka, S., Terashima, T., Ouchi, M. \& Sawamoto, M. Design of AB divinyl 'template monomers' toward alternating sequence control in metalcatalyzed living radical polymerization. Polym. Chem. 2, 341-347 (2011).

19. Ouchi, M., Terashima, T. \& Sawamoto, M. Precision control of radical polymerization via transition metal catalysis: from dormant species to designed catalysts for precision functional polymers. Acc. Chem. Res. 41, 1120-1132 (2008).

20. Ouchi, M., Terashima, T. \& Sawamoto, M. Transition metal-catalyzed living radical polymerization: toward perfection in catalysis and precision polymer synthesis. Chem. Rev. 109, 4963-5050 (2009).

21. Tsarevsky, N. V. \& Matyjaszewski, K. 'Green' atom transfer radical polymerization: from process design to preparation of well-defined environmentally friendly polymeric materials. Chem. Rev. 107, 2270-2299 (2007).

22. Matyjaszewski, K. \& Tsarevsky, N. V. Nanostructured functional materials prepared by atom transfer radical polymerization. Nat. Chem. 1, 276-288 (2009).

23. Butler, G. B. Cyclopolymerization. J. Polym. Sci. Part A: Polym. Chem. 38, 3451-3461 (2000).

24. Yokota, K., Haba, O., Satoh, T. \& Kakuchi, T. Cyclopolymerization. Chirality induction for the synthesis of chiroselective corand/ionophore ligands. Macromol. Chem. Phys. 196, 2383-2416 (1995).

25. Tunca, U. \& Yagci, Y. Crown ether-containing polymers. Prog. Polym. Sci. 19, 233-286 (1994)

26. Kodaira, T. Structural control during the cyclopolymerization of unconjugated dienes. Prog. Polym. Sci. 25, 627-676 (2000).

27. Choi, S.-K., Gal, Y.-S., Jin, S.-H. \& Kim, H.-K. Poly(1,6-heptadiyne)-based materials by metathesis polymerization. Chem. Rev. 100, 1645-1681 (2000).

28. Jia, Y., Liu, L., Lei, B., Li, J. \& Zhu, X. X. Crown ether cavity-containing copolymers via controlled alternating cyclopolymerization. Macromolecules 44, 6311-6317 (2011).

29. Ochiai, B., Ootani, Y. \& Endo, T. Controlled cyclopolymerization through quantitative 19-membered ring formation. J. Am. Chem. Soc. 130, 10832-10833 (2008).

30. Narumi, A. et al. Enantiomer-selective radical polymerization of bis(4vinylbenoate)s with chiral atom transfer radical polymerization initiating system. Macromolecules 40, 9272-9278 (2007).

31. Nakano, T., Okamoto, Y., Sogah, D. Y. \& Zheng, S. Cyclopolymerization of optically active (-)-trans-4,5-bis(\{methacryloyloxy\}diphenylmethyl)-2,2dimethyl-1,3-dioxacyclopentene through radical and anionic mechanisms given highly isotactic polymers. Macromolecules 28, 8705-8706 (1995).

32. Kakuchi, T., Haba, O. \& Yokota, K. Cyclopolymerization of divinyl ethers. Synthesis and the cation-binding property of poly(crown ether)s. Macromolecules 25, 4854-4858 (1992).

33. Coates, G. W. \& Waymouth, R. M. Enantioselective cyclopolymerization: optically active poly(methylene-1,3-cyclopentane). J. Am. Chem. Soc. 113, 6270-6271 (1991).

34. Coates, G. W. \& Waymouth, R. M. Enatioselective cyclopolymerization of 1,5-hexadiene catalyzed by chiral zirconocenes: A novel strategy for the synthesis of optically active polymers with chirality in the main chain. J. Am. Chem. Soc. 115, 91-98 (1993).

35. Fox, H. H. \& Schrock, R. R. Living cyclopolymerization of diethyl dipropargylmalonate by $\mathrm{Mo}(\mathrm{CH}-t-\mathrm{Bu})(\mathrm{NAr})\left[\mathrm{OCMe}\left(\mathrm{CF}_{3}\right)_{2}\right]_{2}$ in dimethoxyethane. Organometallics 11, 2763-2765 (1992).

36. Kumar, P. S., Wurst, K. \& Buchmeiser, M. R. Factors relevant for the regioselective cyclopolymerization of 1,6-heptadiynes, $\mathrm{N}, \mathrm{N}$-dipropargylamines,
$N, N$-dipropargylammonium salts, and dipropargyl ethers by $\mathrm{Ru}^{\mathrm{IV}}$-alkylidenebased metathesis initiators. J. Am. Chem. Soc. 131, 387-395 (2009).

37. Kopolow, S., Hogen Esch, T. E. \& Smid, J. Poly(vinyl macrocyclic polyethers) Synthesis and cation binding properties. Macromolecules 6, 133-142 (1973).

38. Warshawsky, A., Kalir, R., Deshe, A., Berkovitz, H. \& Patchornik, A. Polymeric Pseudocrown ethers. 1. Synthesis and complexation with transition metal anions. J. Am. Chem. Soc. 101, 4249-4258 (1979).

39. Alexandratos, S. D. \& Stine, C. L. Synthesis of ion-selective polymer-supported crown ethers: a review. React. Funct. Polym. 60, 3-16 (2004).

40. Gao, H. \& Matyjaszewski, K. Synthesis of functional polymers with controlled architecture by CRP of monomers in the presence of cross-linkers: From stars to gels. Prog. Polym. Sci. 34, 317-350 (2009).

41. Terashima, T. \& Sawamoto, M. Microgel-Core Star Polymers as Functional Compartments for Catalysis and Molecular Recognition. in Progress in Controlled Radical Polymerization: Materials and Applications. (eds Matyjaszewski, K., Sumerlin, B. S. \& Tsarevski, N. V.) ACS Symposium Series 1101, 65-80 (2012).

42. Terashima, T., Nomura, A., Ito, M., Ouchi, M. \& Sawamoto, M. Star-polymercatalyzed living radical polymerization: microgel-core reaction vessel by tandem catalyst interchange. Angew. Chem. Int. Ed. 50, 7892-7895 (2011).

43. Baek, K.-Y., Kamigaito, M. \& Sawamoto, M. Star-shaped polymers by metalcatalyzed living radical polymerization. 1 . Design of $\mathrm{Ru}(\mathrm{II})$-based systems and divinyl linking agents. Macromolecules 34, 215-221 (2001).

44. Ando, T., Kamigaito, M. \& Sawamoto, M. Macromolecules 31, 6708-6711 (1998).

45. Han, S., Hagiwara, M. \& Ishizone, T. Macromolecules 36, 8312-8319 (2003).

46. Lutz, J.-F. Polymerization of oligo(ethylene glycol) (meth)acrylates: Toward new generations of smart biocompatible materials. J. Polym. Sci. 46, 3459-3470 (2008).

\section{Acknowledgements}

This research was supported by the Ministry of Education, Science, Sports and Culture through a Grant-in-Aid for Creative Scientific Research (18GS0209) and Young Scientist (B) (no. 20750091), and by the foundation for the promotion of ion engineering, for which T.T. is grateful. We also thank Prof. Kenji Matsuda and Prof. Takashi Hirose (Department of Synthetic Chemistry and Biological Chemistry, Kyoto University) for the molecular dynamics calculation, and Mr. Yuta Koda for technical supports on ${ }^{23} \mathrm{Na}$ NMR measurements.

\section{Author contributions}

T.T. and M.K. designed all of experiments. M.K., Y.M. and H.Y. carried out the experiments. T.T. and M.S. conceived and supervised the project and wrote the paper.

\section{Additional information}

Supplementary Information accompanies this paper at http://www.nature.com/ naturecommunications

Competing financial interests: The authors declare no competing financial interests.

Reprints and permission information is available online at http://npg.nature.com/ reprintsandpermissions/

How to cite this article: Terashima, T. et al. Polymeric pseudo-crown ether for cation recognition via cation template-assisted cyclopolymerization. Nat. Commun. 4:2321 doi: 10.1038/ncomms3321 (2013). 